Roger Williams University

DOCS@RWU

January 2008

\title{
Catalogers explore a new frontier: establishing a NEASC evidence center
}

Mary J. Wu

Roger Williams University, mwu@rwu.edu

Follow this and additional works at: https://docs.rwu.edu/librarypub

\section{Recommended Citation}

Wu, M. J. (2008). Catalogers explore a new frontier: establishing a NEASC evidence center. Retrieved from https://docs.rwu.edu/librarypub/9

This Article is brought to you for free and open access by the University Libraries at DOCS@RWU. It has been accepted for inclusion in Library Faculty Publications by an authorized administrator of DOCS@RWU. For more information, please contact mwu@rwu.edu. 


\section{Catalogers Explore a New Frontier: Establishing a NEASC Evidence Center}

\section{Introduction:}

A survey conducted in 1998 by Lois Buttlar and Rajinder Garcha demonstrates a critical change in the role and function of catalogers in academic libraries as the result of an increased availability of information technology ${ }^{1}$. Catalogers are no longer confined in their offices, focusing exclusively on creating bibliographic records for materials provided by the library. Rather, as experts in knowledge management, catalogers are now provided with an abundance of opportunities in developing new metadata standards, organizing institutional repositories and classifying information on the internet.

Furthermore, at their own institutions, they are more often summoned to assist in tasks essential to the goals of the institution. Provosts, deans and university presidents are beginning to recognize the value and usefulness of catalogers.

This paper gives an account of a project in which catalogers played a crucial role in establishing and managing the online NEASC (New England Association of Schools and Colleges) Evidence Center to assist in the reaccreditation process for Roger Williams University. It focuses on the methods used to ensure the effective organization of the large number of records amassed for the NEASC visit within an existing cataloging database, including application of the Anglo-American Cataloging Rules and the MARC bibliographic format for consistent and accurate description of the records and effective searching and retrieval of these records. Blackboard software was employed, but other document sharing systems could have served just as well. Issues of management related to record collection, retrieval and long-term preservation are also explored. This account aims to give basic guidance to others who may be venturing into a similar project. It is a testament to the rising, rather than the diminishing, importance of the cataloging as a professional specialty within academic librarianship.

\section{The Project}

\section{Background}


Roger Williams University in Bristol, Rhode Island is an institution with approximately 3,600 undergraduate and 600 graduate students, which focuses on liberal arts education but also includes five additional professional schools. In 2004 Roger Williams began its application for reaccreditation by NEASC. A portion of the application included a thorough Self Study Report that addressed how the institution met the eleven standards set by NEASC for accreditation. Accompanied by extensive supporting documents, the Report was submitted in the fall of 2006. Soon afterwards, a team of evaluators from peer universities conducted a follow-up campus visit.

A NEASC Steering Committee, led by the Associate Provost, was formed to oversee the entire application process. The research, analysis and documentation of the information gathered for addressing each standard were carried out by eleven task forces with chairs appointed by the Associate Provost. The Steering Committee decided on the creation of an online NEASC Evidence Center for posting documents that were either cited as evidence in the Self Study Report, scheduled for display in the NEASC Team Workroom, or regarded as useful information for writing the report.

Centralizing the management and distribution of the documents that played a part in seeking reaccreditation by using web technology presented several distinct advantages. First, utilizing an online system increased the efficiency and effectiveness of document submission, organization and retrieval. For instance, typical impediments such as handling massive printed volumes of information, dealing with multiple document formats and managing varied title references for one document were easily avoided or handled. Secondly, online access provided timely accessibility and accurate retrieval of document content. Task force members could easily determine if evidence they needed had already been submitted by another task force, and they could readily use the online Center for compiling the Self Study Report from home or from their offices. Members of the visiting team, upon receiving the Self Study Report, could also quickly access the full-text version of the supporting documents prior to arriving on campus. Thirdly, designating one person to be responsible for management of the Evidence Center ensured better accountability and quality control than might be achieved by allocating duties to 
various individuals who might have different perceptions of the goals and objectives of the undertaking.

The Dean of the Library, a member of the Steering Committee, chose the Library's Cataloging Department to oversee the management of the documents. The goals articulated for the project were:

1. To ensure fast and accurate retrieval of documents collected for supporting the NEASC accreditation process;

2. To preserve the documents for short and long-term use;

3. To document the course and results of the project and gain experience that could be applied in preparation for the next accreditation visit in ten years

The Cataloging Department staff involved with the project consisted of a Catalog/Database Management Librarian and three Copy Catalogers (one full-time, two part-time).

Providing effective access to the documents presented several challenges, the most notable being employment of the Blackboard Learning System, a commercial product from Blackboard Inc. chosen by the Steering Committee as a web-based platform to carry out the project. The system had been widely used as a course communication tool between faculty and students at Roger Williams for several years. Its grouping, linking and posting capabilities were excellent. The familiarity of using the software by task force members was an undeniable benefit. Therefore the Steering Committee decided that it would be best to employ Blackboard as the basic tool for the NEASC document project, and the library staff worked with the Blackboard system as a given. However, the Blackboard software was not designed to perform library-oriented functions. A separate records-management system for effective searching, retrieval, preservation and use of the documents needed to be instituted preceded by promotion of a systematic method for depositing documents at the Library. Since Roger Williams University had been founded fairly recently in 1956, a records management program to preserve its history had not yet been seriously considered and items for the Library's archives were received sporadically. Much effort by cataloging staff was envisioned to encourage 
college personnel to deposit NEASC materials. The Evidence Center was to be primarily concerned with records (papers and other media of recorded information) produced in the course of activities at Roger Williams University, including copies of active records held in administrative offices. Most were inactive records that should have been transferred to the archives at a scheduled time in the past if an established records management program had been in place.

\section{Document Arrangement and Description}

The literature on the principles of records management is extensive but often highlights the importance of gaining both physical and intellectual control over the items. The key components that ensure strong bases for records administration as defined by Ineke Deserno and Donna Kynaston are records registration, classification and application of metadata $^{2}$. In addition, procedures defining the best practices established by archives, museums and libraries provide step-by-step instructions for arranging and describing archival documents ${ }^{34}$.

The Cataloging Department started receiving document submissions in the spring of 2005. Guided by the Steering Committee, task force chairs determined what, where and how those documents should be acquired. Electronic documents were preferred over their print counterparts. A document that existed only in paper format was digitized by the library staff if more than one task force requested it.

The first step for the manager of the Evidence Center was to establish an overall structure which divided the mass of documents into meaningful series (or units) so that they could be effectively described and utilized. In line with suggestions by Gregory S. Hunter on setting up appropriate levels of records arrangement ${ }^{5}$, an online NEASC Documents Submission Form for obtaining information on each document was created and widely disseminated by the Cataloging Department. The hope was that this form would collect suppliers' contact information as well as document information, including the title, format, original creator and the name of the task force that requested it. However, more

often than not those submitting documents would insert a note or send an email to notify the cataloging staff of the submission instead of filling out the form. In the end, the 
Cataloging Department adopted a certain degree of flexibility towards the use of the form as long as sufficient information was supplied by other means.

Eleven units were set up in the online Evidence Center on Blackboard for listing documents for each NEASC Standard. While approximately 250 documents or groups of documents were collected, there was a total of 386 title entries contained in the eleven units, since certain documents were cited by more than one task force. All electronic documents were uploaded and saved on the Roger Williams University Blackboard server. As shown in figure1, a three or four layered structure was implemented to arrange the documents. The majority of documents were able to be accessed by clicking on the title at the third layer of the structure. Some of them, however, were available at the fourth layer because they needed to be sub-grouped. For example, instead of assigning eight title entries for the strategic plans of individual schools, those plans were sub-grouped under Strategic Plans of Schools and Libraries to avoid a long and cumbersome list on the main access layer.

A unique ID was assigned to all documents upon their entrance into the system. The ID consisted of the task force name and a document number for identifying the unit and the document it contained. If a document already existed in the system and was submitted or requested at a later time by a different task force, an additional ID was assigned. Therefore, a document used by more than one task force had multiple IDs. All IDs assigned were permanent and could not be reused after a document was withdrawn from the system.

Yet, building a structure in Blackboard to arrange documents was but the first step in the process. The lack of a searching capability hindered the effective and accurate retrieval of records. The cataloging staff had difficulty in maintaining the documents when browsing the long list of titles contained in the eleven units on Blackboard. On the public services front, members of the Reference Department needed a system that would enable them to help task force members find the documents. Using a tool such as Microsoft Access to create a relational database that the public could access required time and programming skills that the Cataloging Department lacked.

As an alternative, the Cataloging Department explored the possibility of cataloging the documents in the MARC (Machine Readable Cataloging Record) format, according to 
Anglo-American Cataloging Rules ( $2^{\text {nd }}$ edition) and other Library of Congress metadata standards and including the resulting records in the Library's online catalog. The document mark-up and cataloging standards were the standard well-honed, and timehonored mechanisms used by the cataloging staff for organizing many different types of materials, provided a variety of effective access points for materials, and allowed easy retrieval for everyone - the library staff, as well as the task force members - through the very familiar, but highly sophisticated, search and retrieval capabilities of the online library catalog. It was imperative to employ such a system which greatly reduced the likelihood of document misfiling by cataloging staff, and more importantly, it expedited document retrivals requested by the visiting team. An added bonus of using an existing library automation system was the availability of the circulation function for checking out the physical NEASC documents!

However, the problem in applying the library standards was that the type of the material to be organized did not fall easily into regular cataloging categories. The documents collected for this particular project were single-item manuscripts. Creating individual MARC bibliographic records to describe each manuscript in a collection was neither the norm of cataloging practice nor a possibility due to the sheer number of documents involved. Instead, creating MARC records that described the unit as a whole and treated documents contained in the unit as related bibliographic entities was determined to be the most appropriate approach.

Eleven cataloging records were created in the catalog to describe each unit (See Figure 2 for an example of one of these records). The primary access points were titles that led to the discovery of the entities located on two hierarchical layers: the unit and the individual document. Titles of the eleven NEASC standards used to label the eleven units were placed in the MARC 245 Title Statement Field as collection level titles. The titles of individual documents representing the third layer entity were placed in the 740 Related Title Field followed by a format description, another important piece of information. The 740 title field's keyword search option allowed greater flexibility for search queries. For example, a 740 search result could be used to determine whether a document was located in more than one NEASC unit. This particular search query was helpful in the selection 
of the most commonly cited documents. These documents along with others deemed significant were later displayed in the NEASC Team Workroom. ${ }^{6}$

\section{Procedures}

The task of managing the NEASC Evidence Center was well integrated into the regular cataloging workflow with designation as a priority duty. A portion of the documents grouped by the eleven standards was assigned to each staff member, who was then fully responsible for updating the appropriate unit-level records and making the documents accessible. Step-by-step procedural guidelines helped to standardize the process and ensure quality control. According to these procedures, staff would first search the catalog to determine if a document had already been submitted before placing the title into the appropriate unit-level record. Staff were instructed to note in the record if special software was needed to open a document. In addition, it was particularly important for staff to follow the procedures for indicating the appropriate title, since titles could be taken from various sources, such as the caption, heading, and file name used to save the document. The order of preference prescribed was caption, heading and running titles. In some cases, the document provided no information, so the titles given by the document supplier were used. File names were not used as titles because most often they were abbreviations and could hinder document retrieval.

\section{Document Access}

Access to electronic documents located in the online Evidence Center was restricted to task force members and members of the NEASC visiting team as some contained confidential information about the university. On certain occasions, people needing documents in the collection for general purposes found these items by searching the catalog. A written NEASC Document Access Policy helped explain these restrictions. The members of the NEASC visiting team received the Self-Study Report along with instructions for using the Online Evidence Center prior to their arrival. To assist the team in accessing the supporting evidence, notes indicating the location of documents, such as "See Strategic Plans of Academic Schools and Library, Standard one: Mission, Doc. 20" were inserted in the text of the Report where the documents were referenced. In addition, 
eleven "Evidence Indices" arranged by document number were placed in the NEASC Team Workroom for quick browsing.

\section{Record Preservation}

In her 1998 article, Sally McInnes articulated that unlike paper records whose continued existence does not rely upon sophisticated preservation procedures, electronic records need to be strategically managed to ensure their preservation ${ }^{7}$. The majority of the records collected for the Evidence Center were in electronic format. However, in addition to ensuring long-term access to the contents contained in the documents, preserving the contextual aspect of the Evidence Center was also essential since the model could well serve the next accreditation effort.

Several types of solutions for dealing with the long-term preservation of digital records were suggested by Dimitri Stamatiadis in his 2005 article. Among the simple solutions were keeping all data "live" in the production database and using a time capsule to maintain all obsolete hardware and software to allow for legacy data access ${ }^{8}$. Although this approach did not appear to be long-term archiving, it was used to save a backup replica of the Evidence Center on a Roger Williams University server for ongoing access. In addition, all units in the Center will be migrated to a compact disc as another longterm preservation measure. The $\mathrm{CD}$, along with other documentation pertaining to the accreditation, will ultimately be transferred to the Archives in the library as a collection for NEASC accreditation. A full bibliographic record will be created in the OCLC WorldCat database to describe the collection. The bibliographic record will then be downloaded to the local cataloging system for bibliographic control. The finding aid for the collection will be an "Evidence Index".

\section{Summary}

\section{Lessons Learned}

Three major challenges of which other organizations should be aware emerged during the planning and execution stages of establishing the NEASC Evidence Center. The first occurred at the very outset of the entire accreditation preparation process, when the 
Cataloging Department underestimated the need for administrative support and neglected to explain the process thoroughly to upper level leadership. As a result, some task force chairs did not understand the full breadth of the plan and submitted documents that required cataloging staff to make major adjustments to the organizational structure of the Center.

Communication was another important and challenging aspect of the project. Although several levels and types of communication tools were employed, getting messages to all appropriate parties was difficult. All participants in the task forces were occupied by their daily routines and were hard to reach, especially when messages were not sent by a top ranking official. In addition, thinking that documents would be forwarded to Cataloging without staff sending several reminders was an unrealistic expectation. Therefore, some documents arrived at the last minute and had to be added under less rigorous conditions of quality control.

Finally, while the project undoubtedly proved its worth, a well planned assessment to obtain the knowledge and experience needed for the future was not conducted. Everyone was grateful for the successful completion of the accreditation process, but very few were eager to go back to examine it.

\section{Rewards Gained from the Project}

The effective organization of information for easy retrieval requires knowledge of data processing, data element mapping and integration, and structural design of the system. It is generally assumed that these skills are found exclusively in information technology departments. Despite having amassed a century's worth of experience in knowledge analysis, organization, and access in developing the library catalogs, catalogers are often overlooked when resources outside of library collections need to be organized. Here lies the paradoxical irony that Robert Rodriguez pointed out in his article more than ten years ago: in this changing world of information management, the growing importance of cataloging is accompanied by a declining importance of catalogers ${ }^{9}$. Following the misconception that computers are the single solution to all information retrieval problems and that cataloging has nothing to do with service, the number of professional catalogers has dropped alarmingly. After a thorough study published in 2005, Joan M. Leysen and 
Jeanne M.K. Boydston predicted that fewer professional catalogers will be available to provide necessary leadership and direction in meeting the challenges of rapid technological change and future information organization and retrieval needs ${ }^{10}$. So how do we promote the value of cataloging and begin to foster its strong commitment to service? In her 2005 article, Carol A. Hryciw-Wing pointed out various activities that engage catalogers' skills in the arena of public services. One such suggestion is to initiate projects that relate specifically to the interests of students, faculty and other institution members. In this way, patrons of the library will be able to appreciate and understand the cataloging service more directly ${ }^{11}$.

Indeed, providing access to supporting documents for NEASC accreditation opened the door for catalogers at Roger Williams University to work directly with the public. The opportunity to collaborate with administrators, faculty and staff gave the Cataloging Department a more visible presence in the university community. The value of the cataloging service and the strength of catalogers in information management were recognized as important assets of the university ${ }^{12}$. Moreover, the project's successful completion gave the Cataloging Department a reassurance of the usefulness and value of its work.

\footnotetext{
${ }^{1}$ Lois Buttlar \& Rajinder Garcha, "Catalogers in Academic Libraries: Their Evolving and Expanding Roles," College \& Research Libraries 59, no. 4 (July 1998): 311-320.
} 
${ }^{2}$ Ineke Deserno \& Donna Kynaston, “A Records Management Program That Works for Archives," The Information Management Journal 39, no. 3 (May-June 2005): 61.

${ }^{3}$ Gregory S. Hunter, Developing and Maintaining Practical Archives: a How To-Do-It Manual, $2^{\text {nd }}$ ed. (New York: Neal-Schuman Publishers, 2003).

${ }^{4}$ Gordon McKenna, ed., Spectrum: the UK Museum Documentation Standard. Online. MDA (Cambridge, England) Available: http://www.mda.org.uk/spectrum.htm (May 16, 2007)

${ }^{5}$ Gregory S. Hunter, Developing and Maintaining Practical Archives: a How-To-Do-It Manual, $2^{\text {nd }}$ ed. (New York: Neal-Schuman Publishers, 2003), P. 115-129.

${ }^{6}$ The HELIN OPAC provides title search examples (e.g. search for title "NEASC standard") available: http://helin.uri.edu/ (May 16, 2007)

${ }^{7}$ Sally McInnes, "Electronic Records: the New Archival Frontier," Journal of the Society of Archivists 19, no. 2 (1998): 211.

${ }^{8}$ Dimitri Stamatiadis, "Digital Archiving in the Pharmaceutical Industry," The Information Management Journal 39, no. 4 (July/August 2005): 56.

${ }^{9}$ Robert Rodriguez, “Ten Tips for Cataloger Survival,” Technical Services Quarterly 93, no. 3 (1992): 15.

${ }^{10}$ Joan M. Leysen \& Jeanne M.K. Boydston, "Supply and Demand for Catalogers:

Present and Future," Library Resources \& Technical Services 49, no. 4 (2005): 260.

${ }^{11}$ Carol A. Hryciw-Wing, "Catalogers Exposed! Library Users Stunned by Revelations," Technicalities 25, no. 4 (2005): 11.

${ }^{12}$ The Catalog/Database Librarian received a merit pay award in May, 2007 for her exemplary contributions in the accreditation process. 